This article has been published in Journal of Institutional Economics

Villamayor-Tomas, S. (2018). Disturbance features, coordination and cooperation: an institutional economics analysis of adaptations in the Spanish irrigation sector. Journal of Institutional Economics, 14(3), 501526. https://doi.org/10.1017/S1744137417000285. This version is free to view and download for private research and study only. Not for re-distribution, re-sale or use in derivative works. @ Millennium Economics Ltd 2018. 


\title{
Disturbance features, coordination and cooperation: an institutional economics analysis of adaptations in the Spanish irrigation sector.
}

\author{
SERGIO VILLAMAYOR-TOMAS \\ Institute of Environmental Science and Technology (ICTA), Autonomous University of \\ Barcelona, Barcelona, Spain
}

\begin{abstract}
:
This paper explores associations between disturbances and cooperative responses in a selection of irrigation associations from Spain. Transaction costs and collective action theories are used to characterize disturbances and responses. Disturbances are characterized by looking at the uncertainty they generate, their frequency, the distance of the transacting partners they affect, and their impact on asset specific transactions. Responses are assessed based on the collective action tasks they involve and classified into coordination and cooperation responses. A Qualitative Comparative Analysis confirms two pathways that are sufficient for the emergence of cooperation responses. The first path is congruent with transaction costs theory, and points to disturbances that are frequent and asset specific; the second path supports relational theory, and points to disturbances that emerge progressively from within the system. Other patterns include the tendency of the irrigation associations to delegate on external entities when the disturbances are external and occur frequently; and the adaptation of existing institutions when the disturbances are internal and progressive.
\end{abstract}

\section{Introduction}

Contemporary societies are increasingly exposed to climate change but also other threats such as demographic changes or market crises that are the result of socioeconomic development and manifest at multiple scales. This situation has generated a new interest in understanding the manner in which communities organize in response to different types of menaces in different contexts (UN/ISDR 2004). Research in natural resource management has been particularly productive in that regard. According to ecology and complex systems scholars, different disturbances may require different responses by communities, but there may be also commonalities (Berkes et al. 2003, Anderies et al. 2006). Also, a number of scholars studying natural resource management have pointed to the collective-action problems involved in adapting to changes, as well as the transaction costs of solving those problems (Lam 2006, Villamayor-Tomas 2014, Araral 2013b). All this scholarship calls for a systematic characterization of disturbances and the collective responses they trigger.

This paper advances an institutional economics approach to the study of climate change adaptation by local communities (Araral 2013b). Specifically, the paper aims to understand adaptation to climate change by looking at a broad spectrum of disturbances, including climate-related disturbances like droughts and floods as well as other disturbances. The research questions that drive the study are: Are there identifiable patterns in the way local communities collectively respond to disturbances of different nature, including droughts 
and floods but also others? Do disturbance characteristics affect the way the communities respond? If so, how?

Empirically, the study relies on a unique dataset of 50 disturbance-collective response cases obtained from the study of 5 Spanish irrigation associations (WUAs). Studying adaptability in the irrigation context is useful for several reasons. Irrigated agriculture is one of the economic activities where the impact of climate change disturbances is most evident (Boken et al. 2005). Second, an important part of the institutional economics theory in the field of natural resource management is based on the study of local irrigation governance (Ostrom et al. 1994). Spain is well recognized for the long tradition and autonomy of its irrigation associations (Ostrom 1990), many of which have successfully evolved to combat a variety of threats such as droughts, floods, wars, and plagues over centuries. In the last 20 years, however, a series of severe droughts and the growth of cities and industry in Spain have resulted in a new concern about the ability of the irrigation sector to adapt (Lopez Galvez and Naredo 1997). Understanding how the irrigation communities cope with those threats can be particularly illustrative of patterns of adaptation to different types of disturbances.

Theoretically, the study relies on transaction costs and collective action theories (Williamson 1985, Ostrom et al. 1994). Transaction costs theory is used to characterize disturbances by looking at the uncertainty they generate, their frequency, the distance of the transacting partners they affect, and their impact on asset specific transactions. Collective action theory is used to feature responses based on the collective action tasks they involve. Relationships between different types of disturbances and responses are then explored via Qualitative Comparative Analysis (QCA).

\section{Theoretical framework: transactions, coordination and cooperation}

Theory on tradable property rights (Coase), institutional design principles (Ostrom), and transaction costs (Williamson), also coined as the COW framework, can constitute a foundation for the analytics of climate change adaptation (Araral 2013b). A few studies on climate adaptation in the irrigation sector have set the path in that direction (Araral 2013a, Varela-Ortega et al. 2016, Villamayor-Tomas 2014). This study builds on those efforts. Specifically, the study adopts a model according to which the responses of self-organized communities to disturbances depends on the extent to which the disturbances motivate cooperative responses and the costs of collective action (Fleischman et al. 2010).

\subsection{Disturbance features and the motivation for cooperation}

Disturbance can be defined as an "event that disrupts social or ecological communities, resulting in changes to the physical or social environment” (Fleischman et al. 2010). Different authors have theorized about types of disturbances. Salafski et al. (2008), for example, distinguish between threats vs. stresses; and Schoon and Cox (2011) classify disturbances depending on aspects such as intensity or frequency.

Transaction cost theory can be used to reason about the relationship between disturbance features and the motivation for cooperation. Transaction costs scholars are interested in the governance conditions that make transactions between economically 
motivated agents to function efficiently given the risk that agents behave opportunistically (Williamson 1985). Hagedorn (2008) developed the concept of nature-related transactions (nr-t) to recognize the mediating role of physical conditions in human interactions. According to the concept, many interactions between individuals happen only indirectly, as they use shared biophysical resources. Thus, it is not only necessary to study the characteristics of the transactions resulting from person-to-person interactions, but also those that emerge from person-to-nature-to-person interactions. This concept applies particularly well to the study of irrigation systems and associations, where interactions between farmers are mediated by the use of shared infrastructure and water resources.

The scholarship applying transaction costs economics to environmental governance has identified a number of nr-t features and theorized about their impact on the motivation for cooperative governance structures (Thiel et al. 2016). The paragraphs that follow describe these features and explore their applicability to characterize disturbances and their impact on the motivation for cooperative responses in the irrigation context.

In an asset specific transaction, the investments made to accomplish the transaction are rather unique to the partners involved. If the transaction fails, partners are likely to incur losses "because, for example, alternative transacting partners cannot deliver the same good or service or because they do not have access to the same assets” (Thiel et al. 2016), p. 12). To minimize the risk of failure, partners may be particularly willing to engage in long-term cooperation under a common organization as opposed to ad hoc contracting (Williamson 1991). Irrigation associations are a good example of the relevance of asset specificity. Farmers in irrigation systems engage in three fundamental nature related-transactions: water use, water allocation and infrastructure maintenance (Tang 1992). Water use is a nr-t because the amount of water withdrawn by a farmer in an irrigation system affects the amount of water that other farmers in the system can use. Water allocation is also a nr-t because farmers in an irrigation system usually cannot withdraw the water all at once, i.e., some farmers will not be able to use water if other farmers are doing it already. Infrastructure maintenance is also a $\mathrm{nr}-\mathrm{t}$ because the infrastructure is shared, so if a farmer does not maintain it, that will affect not only him but also other farmers. All three naturerelated transactions are highly asset specific. Infrastructure investments of a farmer in the irrigation infrastructure cannot be recovered if other farmers fail to invest too and/or if the farmer moves elsewhere. Similarly, there are cropping investments every year that will not be recovered if there are water use or water allocation issues. Irrigation associations secure all those investments by integrating farmers within a cooperative regime of water and infrastructure management rules; however, some disturbances can challenge the performance of those rules. The reduction of water availability during a drought, for example, can increase opportunistic behavior among farmers and decrease compliance with water management rules (Osés-Eraso et al. 2008). Similarly, urbanization can decrease the willingness of farmers to keep investing in the shared infrastructure (Cox 2014). The nonrecoverability loses if water use, water allocation or infrastructure maintenance transactions fail may constitute a sufficient motivation for farmers to engage cooperative responses that secure those transactions.

Environmental uncertainty refers to the occurrence of "random acts of nature" that affect transactions (Williamson, 1985, p. 57). As posed by Williamson, the risk of opportunistic behavior by partners in a transaction increases with environmental uncertainty. In highly uncertain situations, partners may prefer cooperating within an overarching organization rather than just engaging in ad hoc contracting (Williamson 
1991). Nature-related transactions, like those featured in irrigation systems, are particularly vulnerable to uncertainty due to their exposure to environmental disturbances (Thiel et al. 2016). One way to assess the uncertainty generated by a disturbance is by looking at its intensity. Disturbance intensity can be defined as the deviation from a norm given a time frame (Schoon and Cox 2011). Changes that occur progressively over time (e.g., demographic transitions) may represent significant deviations from the norm in the long term; however, deviations are small in the short term and therefore relatively predictable over time. Alternatively, intense or sudden changes (e.g., a flood) are difficult to predict and generate information gaps. In irrigation systems, gaps would include the lack of information about the impact of the disturbance on the infrastructure, resource availability, or the behavior of farmers, for example. The risk that rent seekers use those information gaps opportunistically, would motivate a majority of farmers to engage in cooperation and respond collectively to the disturbance.

The frequency of transactions also motivates the establishment of cooperative arrangements. Everything else being equal, the frequency of a transaction contributes to the profitability of scale economies if partners decide to cooperate and integrate the transaction in a common organization (Williamson 1991). This logit can be extrapolated to the study of disturbances in the irrigation context: disturbances that occur frequently facilitate that farmers standardize their responses under a common cooperative strategy (Janssen et al. 2007). However, there is a caveat to bear in mind. Frequency is an attribute of intense disturbances (Schoon and Cox 2011). As such, one could argue that that frequency diminishes the uncertainty generated by intense disturbances (Janssen et al. 2007). In that case, the risk of opportunistic behavior and the motivation for cooperation among farmers would also be expected to decrease.

Finally, there is the relational distance between transacting partners. Relational distance depends on social and physical distance. Social distance indicates the existence of heterogeneous interests and experiences among transacting partners. Everything else being equal, interest heterogeneity increases the risk of opportunistic behavior and thus the motivation for cooperation among transacting partners (Thiel et al. 2016). Physical distance is rather related to the location where the costs or benefits of transactions originate. As physical distance increases, so shall the barriers to proper information flows, the room for opportunistic behavior, and the motivation for cooperation (Thiel et al. 2016). In the irrigation context, disturbances caused by agents other than the irrigators (e.g., urbanization) require the accommodation of more heterogeneous interests, than disturbances caused by the irrigators themselves (e.g., rule compliance issues). Similarly, disturbances that originate outside an irrigation system (e.g., droughts) affect partners that are physically more distant than the partners affected when disturbances originate inside the system (i.e., the breakage of a canal).

In synthesis, disturbances can be featured by looking at the uncertainty of their occurrence and their frequency, as well at the asset specificity and distance of the transactions and agents they affect. Uncertainty and distance would increase the risk of opportunistic behavior and in turn the motivation for cooperation; frequency would motivate cooperation mostly by facilitating the development economies of scale; and asset specificity would do ti by increasing the loses in case of failing to cope with the disturbance satisfactorily. Different combinations of these features would motivate cooperative responses in different degree. 


\subsection{The costs of collective action: cooperation vs. coordination responses}

Irrigation associations act as cooperatives to carry some tasks but also allow farmers to coordinate ad hoc with each other or with other agents and organizations to accomplish other tasks. Whether the associations opt for one or the other modes of collective action shall be explained by the transaction costs of each option (Menard 2007). A similar logic can be used to reason about responses to disturbances. As pointed by Araral (2013b), adaptation transaction costs (ATC) "lie at the heart of the analytics of climate adaptation in the local commons, and minimizing ATC holds the key to climate adaptation” (pp. 150) .

The costs of collective action depend on the number of collective tasks to carry. A well established distinction of collective tasks includes communication, decision-making, and enforcement task (Ostrom et al. 1994). The tasks can be cumulative resulting in first, second and further-order collective action processes (Fowler 2005, Panchanathan and Boyd 2004). Coordination is one of the simplest forms of collective action (Bowles 2009). For just coordination to happen communication and/or collective choice among individuals may be sufficient. In game theoretic terms, coordination is associated to the resolution of assurance problems, which are defined by the existence of win-win situations where there are no incentives for some individuals to free ride on the cooperative behavior of others. Everything being equal, once agents coordinate, they shall do it indefinitely. As pointed by Bowles (Bowles 2009), in coordination situations, "the challenge to governance is limited to the less challenging how to get there problem rather than also having to solve the more demanding how to stay there problem” (p 44).

Cooperation goes beyond coordination. Cooperation situations are characterized by the commitment of participants to the maintenance of common pool resources and/or the provision of public goods, such as infrastructure and institutions (Ostrom et al. 1994). Commitment in cooperation situations require enforcement because there is a permanent risk that free riders jeopardize the efforts of those who cooperate (Fehr 2004). Thus, there is the need of interventions that change the structure of payoffs and guarantee individuals not only get there but also stay there. From an institutional perspective, that not only involves communication and collective decision making, but requires enforcement mechanisms (Fowler 2005, Panchanathan and Boyd 2004).

\section{Background}

The study was carried in the North-east of Spain. The area under study expands across the inter basin of the Gállego and Cinca rivers, which are born in the Pyrenees Mountains and flow into the Ebro River by the city of Zaragoza (region of Aragon).

The basics of the organization of irrigation management in Spain are prescribed by law. At the irrigation system level, water is managed by water user associations (WUAs). For that purpose, WUAs are to be organized into an assembly of users, an executive board, a secretary/field guard, and a president. At the basin level, water is managed a river basin organization (RBOs), e.g., the Ebro River Water Agency (CHE). RBOs are responsible for allocating water among the WUAs and the promotion of new infrastructures at the basin level. Also, there are the local governments of the municipalities where the irrigation systems are located, which have authority over drinking water and land use. 


\section{Methods}

The unit of analysis in this study are disturbances-response cases observed in 5 irrigation systems within the area of study. One disturbance may hit different irrigation systems. Also, one irrigation association may develop multiple independent responses to cope with a disturbance. Thus, the number of disturbance response cases in this study results from the number of disturbances identified, the number of irrigation systems hit by each of those disturbances, and the number of responses developed in each system to cope with each disturbance.

The selection of the systems was purposive and aimed to maximize the diversity of disturbances studied, including those linked to climate as well as others. The study of disturbances and responses of different nature over time requires the use of multiple data sources (Araral 2013c). In this study, data was obtained from a thorough review of assembly meeting minutes of the last 20 years in each of the 5 WUAs that manage the selected irrigation systems. The data obtained was used to elaborate a list of disturbances and responses for each system. If one WUA had developed multiple responses to a disturbance, the responses were coded separately if they had been designed and/or implemented independently from each other. For example, the construction of an in-system water reservoir and the development of rules to manage it were coded as one response to droughts, while the development of a drought quota policy was coded as a separate response. Then, the relevance of the disturbances and the independence of the responses were checked through a series of group and individual interviews with executive board members and farmers of the WUAs.

Table 1. Measurement of disturbance features

Disturbance feature Description

\begin{tabular}{|c|c|}
\hline Asset specificity $^{1}$ & $\begin{array}{l}\text { 1= The disturbance threatened either water use and water } \\
\text { allocation transactions, water use and infrastructure maintenance } \\
\text { transactions, water allocation and infrastructure maintenance } \\
\text { transactions, or all of them; } 0=\text { otherwise }\end{array}$ \\
\hline $\begin{array}{l}\text { Intensity } \\
\text { (Uncertainty) }^{2}\end{array}$ & $\begin{array}{l}\text { 1= The disturbance, in all its magnitude, occurred from one } \\
\text { irrigation campaign to the other; } 0=\text { otherwise }\end{array}$ \\
\hline Frequency & $\begin{array}{l}1=\text { The disturbance occurred more than once in the last } 20 \text { years; } \\
0=\text { otherwise }\end{array}$ \\
\hline $\begin{array}{l}\text { Exogeneity } \\
\text { (Distance) }^{3}\end{array}$ & $\begin{array}{l}1=\text { The disturbance was originated outside of the system and/or } \\
\text { by actors not belonging to the irrigation system and association; } \\
0=\text { otherwise }\end{array}$ \\
\hline Response feature & Description \\
\hline Communication & $\begin{array}{l}1=\text { The response required sharing of information among farmers } \\
\text { and with the WUA staff or executive board members; } \\
0=\text { otherwise }\end{array}$ \\
\hline Collective choice & $\begin{array}{l}\text { 1= The response involved a collective decision among farmers in } \\
\text { the WUA (i.e., in an assembly meeting); } 0=\text { otherwise }\end{array}$ \\
\hline
\end{tabular}




\begin{tabular}{ll}
\hline $\begin{array}{l}\text { Rule/contributions } \\
\text { enforcement }\end{array}$ & $\begin{array}{l}\text { 1= The response required the enforcement of rules/contributions } \\
\text { to cope with the disturbance among the irrigation association } \\
\text { members; } 0=\text { otherwise }\end{array}$ \\
\hline
\end{tabular}

${ }^{1}$ : As reasoned in section 2.1, water use, water allocation and infrastructure maintenance are key, highly asset specific transactions in irrigation systems.

2: There are different types of uncertainty and possible proxies for it (Santoro and McGill 2005). As reasoned in section 2.1, intensity is one plausible proxy as events that occur suddenly create more uncertainty than those that unfold progressively, everything else being equal (Janssen et al. 2007). Intensity was also relatively easy to measure in the empirical context of this study.

${ }^{3}$ : As reasoned in section 2.1, exogenous disturbances (i.e., originated outside an irrigation system and/or by non-irrigators), can proxy for social and physical distance of transacting partners, respectively.

${ }^{4}$ In irrigation systems responses may involve the implementation of ad hoc infrastructure investments, rules or both (Araral 2013a). The categories of "rule enforcement” and "contributions enforcement" aim to capture different combinations of those options. Enforcement entails both the existence of monitoring and sanctioning mechanisms (Coleman and Steed 2009).

The analysis proceeded in several steps. First the information about each disturbanceresponse case was coded into different disturbance and response variables based on the reviewed theory (Table 1; see also Appendix for further information and an example of coded case). It is important to note that disturbances that were not intense were not coded for frequency, as the latter is a feature that applies only to intense disturbances given a time frame (Schoon and Cox 2011). Thus the data collection resulted in two datasets, one including all the disturbance-response cases, and one including only the disturbanceresponse cases associated to intense disturbances. As detailed below, the analysis was carried for each dataset separately.

In a second step, the disturbance-response cases were further coded into a "cooperation" outcome variable. Based on the reviewed theory, the presence or absence of enforcement in the response was used as a proxy to distinguish cooperation from coordination responses (Bowles 2009). In irrigation systems and other local common pool resource contexts, enforcement is usually linked to the implementation of resource appropriation rules and/or ad hoc infrastructure contributions (Ostrom et al. 1994). Thus, the cooperation variable was assigned a 1 if "rule enforcement" and/or "contributions enforcement" were present, regardless of whether other collective tasks were also present.

Qualitative Comparative Analysis (QCA) was used to explore associations combinations of disturbance characteristics and cooperation. In QCA, cases are understood as types in terms of the combinations of conditions that characterize them (Ragin 2000). The method does not assume independent effects of conditions on outcomes, which is particularly appropriate in the study of complex socio-ecological processes like those involving adaptation (Lam and Ostrom 2010). Also, QCA offers the possibility to compare small to medium size samples of cases, which was practical for this study due to the difficulties of gathering data about disturbances and responses. QCA has also limits. QCA requires explaining relationships in terms of necessity and sufficiency, which is not how mainstream theory is usually formulated (Ragin 2000). Also, there is the trade-off between number of conditions included in the analysis and the meaning of results, as many conditions produce very complex results that can be hard to interpret theoretically (Schneider and Wagemann 2010).

The analysis proceed in three steps following the QCA standard analysis (Schneider and Wagemann 2010): 
- First, the analysis explored whether any of the disturbance features were necessary and/or sufficient for cooperation to emerge.

- Second, the analysis explored whether combinations of asset specificity, intensity, exogeneity were sufficient for cooperation to emerge with the full dataset of disturbance-response cases. Also, the role of frequency was explored with the subset of cases of intense disturbances.

- Third, the analysis was replicated to explain the absence of cooperation (i.e. the emergence of just coordination), with both the full dataset and the dataset of intense disturbances.

Additionally, the robustness of the results was checked against an aggregated version of the dataset.

\section{Results: Patterns of disturbances and responses}

\subsection{Disturbances}

Data collection resulted in the identification of 17 disturbances (see disturbance names in italics in Table 3). Some disturbances ("lack of labor factor", "crop intensification", "highway/railway development", "landslides" and "droughts") occurred in more than one system, making a total of 29 disturbance cases $\left(\mathrm{n}_{\mathrm{dc}}\right)$.

Disturbances can be grouped depending on the configuration of features (specificity, intensity, frequency and exogeneity) that characterize them.

The group of "Internal and progressive cooperation threats" $\left(\mathrm{n}_{\mathrm{dc}}=7\right)$ includes disturbance that are asset specific, emerged progressively (not intense, and not frequent), and originated from within the system (not exogenous). A paradigmatic example of this type of disturbance is the decrease of labor factor due to the aging and out-migration of population (not exogenous) over the last decades (CESA 2012). This trend unfolded slowly over the last decades (not intense) and is expected to continue at least in the next years (Pinilla Navarro and Saez Perez 2009). Many WUAs in Spain, including the 5 associations under study, rely on labor and monetary contributions from farmers to maintain part of the infrastructure, as well as on their active involvement in the water allocation to guarantee that water flows into the plots at the expected time. The progressive rural depopulation has threatened the effectiveness of those two operations in all 5 systems (high asset specificity).

The other three groups include: "External and frequent disturbances" $\left(\mathrm{n}_{\mathrm{dc}}=6\right)$, "External and infrequent disturbances" ( $\left.\mathrm{n}_{\mathrm{dc}}=5\right)$, and "External and progressive disturbances" $\left(\mathrm{n}_{\mathrm{dc}}=2\right)$. The disturbances in these groups have in common their low asset specificity, i.e., the disturbances threatened only one of the three main transactions carried in the irrigation systems. The momentary breakage of a main canal or the impact of landslides on the infrastructure affected the ability of farmers to allocate water in a timely manner during the irrigation campaign; however, the events did not threaten the ability of farmers to have access to the water they needed by the end of the irrigation campaign or to fulfill regular infrastructure maintenance duties (low asset specificity). Similarly, the flooding of a large number of plots nearby a lake created controversy about whether the affected farmers should keep fulfilling their regular infrastructure duties, but not about whether there would be sufficient water to satisfy needs or whether the water would be properly allocated. 


\subsection{Responses}

The irrigation associations developed an average of two responses per disturbance case, resulting in a pool of 50 disturbance-response cases (Appendix, Table 1). The exploration of collective action tasks resulted in the identification of 6 types of responses (Table 2). The most frequent type of responses is the "delegation on external entity" ( $\left.\mathrm{n}_{\text {disturb-resp cases }}=21\right)$, which involves communication and collective choice tasks. The most frequent collective tasks are communication (present in all instances) and collective choice (present in 36 occasions). This was expected given that communication and collective decision making are two of the most basic forms of collective action (Ostrom et al. 1994). The Outcome splits the sample into 23 cooperation responses and 27 non-cooperation (i.e., just coordination) responses.

As expected, there is a gradient of responses depending on the number of collective action tasks (and costs) involved (see Outcome 2). Cooperation responses, defined by their reliance on enforcement tasks, tend to involve more collective action tasks than coordination responses. An exception to this is the "Ad hoc use of preexisting institution" (cooperation response), which is, by the number of tasks involved, as demanding as "Bargaining with external entity and Delegation on external entity" (coordination responses).

Table 2. Response types ( $\mathrm{n}_{\text {disturbance-response cases }}=50$ )

\begin{tabular}{|c|c|c|c|}
\hline Response type & $\mathbf{n}_{\text {drc }}$ & $\begin{array}{l}\text { Collective action tasks } \\
\text { (and costs) }\end{array}$ & Outcome \\
\hline $\begin{array}{l}\text { Ad hoc internal mitigation } \\
(12 \%)\end{array}$ & 6 & communication $(+)$ & \multirow{3}{*}{$\begin{array}{l}\text { No cooperation } \\
\text { (just } \\
\text { coordination) }\end{array}$} \\
\hline $\begin{array}{l}\text { Bargaining external entity } \\
(14 \%)\end{array}$ & 7 & $\begin{array}{l}\text { communication; collective } \\
\text { choice }(++)\end{array}$ & \\
\hline $\begin{array}{l}\text { Delegation external entity } \\
(28 \%)\end{array}$ & 14 & & \\
\hline $\begin{array}{l}\text { Ad hoc use of preexisting } \\
\text { institution }(16 \%)\end{array}$ & 8 & $\begin{array}{l}\text { communication, rule } \\
\text { enforcement }(++)\end{array}$ & \multirow{3}{*}{ Cooperation } \\
\hline $\begin{array}{l}\text { Infrastructure development } \\
(6 \%) \\
\text { Institutional development } \\
(12 \%) \\
\end{array}$ & 3 & $\begin{array}{l}\text { communication; collective } \\
\text { choice; rule/contribution } \\
\text { enforcement }(+++)\end{array}$ & \\
\hline $\begin{array}{l}\text { Infrastructure \& } \\
\text { institutional development } \\
(12 \%)\end{array}$ & 6 & $\begin{array}{l}\text { communication; collective } \\
\text { choice; rule and contribution } \\
\text { enforcement }(++++)\end{array}$ & \\
\hline
\end{tabular}

\subsubsection{Non-cooperation responses}

Among the non-cooperation (i.e., just coordination) responses, the least demanding type from a collective action perspective is the "ad hoc internal mitigation" type. A paradigmatic example of this type is how two WUAs respond to infrastructure issues due to the occurrence of landslides. When a landslide breaks or blocks the infrastructure, whoever 
first notices it informs the guard, who then carries the cleaning of the canal, sometimes with the help of day-laborers and heavy machinery. This is not perceived by farmers as a rule or a norm but just a "way of doing things". The guards do not have enough monitoring resources to notice the event in time. Communication among the farmers and the guard is thus key for the success of the response. The measures taken by the guard are then reported to all farmers in an ordinary assembly meeting, but only ad hoc, for ratification.

"Bargaining with external entities" and "delegation on external entities" are two types of responses that also entail relatively low collective action costs. In both types, communication happened mostly between farmers and the WUA executive board. The issues were also tackled in general assembly meetings to decide on the most appropriate course of action that the executive board should follow. The responses did not require the enforcement of any rules among the farmers. Regular assembly meetings were also used to control that the executive board had carried it properly. Common examples of the "delegation" type are the use of letters of complaint and the request of investments to the $\mathrm{RBO}$ and local governments in response to river flood damages and breakages in the main canal breakages that connect irrigation systems. An example of the "bargaining" type is the response developed by three WUAs to cope with highway and railway constructions. The constructions intersected the main and secondary canals of the systems. In all systems, the assembly of farmers explicitly authorized the executive board of the WUAs to represent their interests against the construction firms and the department of public works, and guarantee that the affected infrastructure was reconstructed properly.

\subsubsection{Cooperation responses}

Among the cooperation responses, the least demanding response from a collective action perspective is the "ad hoc use of preexisting institution". An example is the response used in 4 of the systems to cope with maintenance problems due to the decreased labor factor. In all systems, the guard has the authority to carry the maintenance works if farmers fail to perform their duties. Then, the costs of the works and a penalty are charged to the farmers. This institution had been developed in the past as a deterrence measure; however, as infractions have become more and more frequent in all 4 systems, the institution has also grown in relevance as a maintenance measure. The measure involves communication and enforcement but not collective choice, as the rule already existed.

Institutional and infrastructure development are the two types of response that entail the highest collective action costs. Both types of responses require the development of monitoring and sanctioning mechanisms, in addition to communication and collective choice. An example of rule development is the quota policy that two WUAs developed in response to droughts. Under the quota policy every farm is allotted a rate of water per hectare. If farmers go over their quotas they are sanctioned. The policy was approved in each association by the ensemble of farmers, and is ratified also every time the executive board needs to use it. An example of infrastructure development is, for example, the remodeling of a river diversion infrastructure in the aftermath of a river flood in one of the WUAs. The remodeling was approved in the assembly, and a special fee was collected among all farmers to finance it.

In a good number of cases, responses involved both infrastructure investments and the development of rules to manage the new infrastructure. A good example is the investments in sprinkler irrigation carried by two WUAs to better cope with the lack of labor, and the 
changes that followed those investments to adapt the water allocation rules to the new technology.

\subsubsection{Combinations of responses}

A fair number of disturbance cases were addressed through both cooperation and coordination responses. WUAs relied only on coordination responses in 13 disturbance cases; only on cooperation responses in 8 disturbance cases; and both on coordination and cooperation responses in 9 disturbance cases. In 7 out of the 9 disturbance cases where cooperation and coordination responses coexisted, the coordination response consisted on the delegation or bargaining with external entities.

\subsection{Analysis of disturbances and responses}

The analysis of necessity yielded relatively clear results. "Asset specificity" and "frequency" have the highest consistency value (around 70\% the disturbance response cases where disturbance was asset specific or frequent the response was cooperative) ${ }^{1}$; however this value is far from reaching 0.9 , which has been used as a threshold of necessity in previous studies (Schneider and Wagemann 2010). All the other consistence scores were below 0.6. Coverage scores (percentage of cases that share a disturbance feature within the group of cooperation responses ) also indicate that none of the features are sufficient by their own to trigger cooperative responses. None of the features reach the coverage threshold of 0.7 (Schneider and Wagemann 2010), although "asset specificity” and (lack of) “exogeneity” are close (0.680 and 0.667, respectively).

Table 3. Configurations of disturbance characteristics that are sufficient for cooperation (complex solution)

$\mathrm{n}_{\mathrm{drc}} \quad$ Disturbances

\begin{tabular}{lll}
\hline Full sample (Cooperation \&asset specific, intense, exogenous) & \\
\hline 1. intense*exogenous & 18 & $\begin{array}{l}\text { Crop intensification, lack of } \\
\text { labor, debtors }\end{array}$ \\
$\begin{array}{l}\text { Consistency: } 0.722 \\
\text { Coverage: } 0.542\end{array}$ & & Droughts, drainage-storm \\
\hline 2. ASSET SPECIFIC*INTENSE*EXOGENOUS & 6 & \\
$\begin{array}{l}\text { Consistency: } 0.714 \\
\text { Coverage: } 0.208\end{array}$ & &
\end{tabular}

Intense disturbances sample (Cooperation $<$ asset specific, frequent, exogenous)

3. ASSET SPECIFIC*FREQUENT*EXOGENOUS 5
Consistency: 1.0
Coverage: 0.5

Note: Upper case letters=presence of condition; Lower case letter=absence of condition. The sufficiency cut for the full sample analysis was downgraded to 0.65 as this cut represented a natural break in the data

\footnotetext{
${ }^{1}$ This result is further confirmed by a Pearson's chi-square test comparing the frequency of cooperation responses across asset and non-asset specific disturbances $\left(\mathrm{Chi}^{2}=8.012, \mathrm{p}\right.$-value $\left.=0.005\right)$.
} 
(Schneider and Wagemann 2010). In the rest of sufficiency analyses 0.7 matched the natural breaks in the data.

The analysis of sufficiency first required synthesizing the data into two truth tables, one for the full sample of disturbances and one for the sub-sample of intense disturbances (see Appendix, Tables 2 and 3). The truth table includes all configurations of disturbance features that are represented by actual cases (i.e., disturbance-response cases) and information about the extent to which the cases are associated to the outcome (i.e., cooperation responses). Then the truth table was minimized via Boolean algebra into a complex solution. The complex solution, is the minimal expression of all configurations that are empirically associated to the outcome. Contrary to the parsimonious solution, the complex solution does not require making ad hoc assumptions about configurations for which no empirical cases have been observed (Ragin and Sonnett 2004). As pointed by (Schneider and Wagemann 2010), both need to be reported (see Appendix, Table 4, for the parsimonious solutions).

As shown in the full sample analysis (solutions 1 and 2 in Table 3), two configurations of disturbance features are sufficient for cooperation. The first of represents cooperation threats that emerge progressively from within the system such as crop intensification; the second refers to sudden external threats such as droughts. The analysis of the intense disturbances sample yields one solution (solution 3). This solution represents frequent and exogenous cooperation threats, and further qualifies the findings from solution 2 . According to the solution, intense and frequent threats such as droughts are sufficient to motivate cooperation, but intense and infrequent threats (such as a leadership crisis) are not.

According to the analysis of necessity for the absence of cooperation (i.e., occurrence of just coordination) no individual condition is necessary. All scores are below 0.7. The highest score holds for the presence of exogeneity (0.731) but still far from the 0.9 threshold. A look at the coverage scores, reveals that the absence of "asset specificity", with a score of 0.720 , is the only sufficient condition for the lack of cooperation. This means that whatever combinations of disturbance characteristics involving the absence of asset specificity is sufficient for the absence of cooperation too. That said, the sufficiency analysis revealed two other sufficiency paths, one per sample (see Table 5 in Appendix).

The first path refers to progressive and external events such as urban pollution. The configuration confirms that progressive disturbances also need to be internal to trigger cooperation, regardless of asset specificity. The second path represents external and infrequent events such as highway/rail way development and confirms that external disturbances are less amenable to cooperation, again regardless of asset specificity.

A cross-tabulation revealed an strong association between the exogeneity of disturbances and the "delegation on external entities" and "bargaining with external entities" coordination responses. Half of the "delegation on external entities" responses (5 out of 11) addressed exogenous and frequent disturbances; while most of the "bargaining with external entities" responses (5 out of 7 ) addressed exogenous and infrequent disturbances.

The robustness check with the aggregated data yielded very similar results (see Appendix, Table 6).

\section{Discussion}


The characterization of disturbances and responses and the QCA results motivate some discussion points. First, the relatively broad scope of disturbances identified raises the question of whether the current focus on climate change of the adaptation policy community is justified scientifically. Climate-related disturbances such as droughts, floods, or algae burst events represented less than $24 \%$ of all disturbance-cases analyzed in this study. Other important disturbances included the lack of labor factor, crop intensification or urbanization issues, to mention a few. The diversity of disturbances identified justifies the interest of understanding climate change adaptation in comparative perspective. One important step in that direction is the development of theoretically and empirically meaningful classifications of disturbances and responses (Salafsky et al. 2008). In this study, the characterization of disturbances according to asset specificity, uncertainty, frequency and distance, allowed the identification of 4 groups disturbances, encompassing 20 of the 29 disturbance cases identified. Similarly, the classification of collective responses according to collective action tasks and costs yielded a scale that can be used for further analytical purposes. Works in the common pool resource tradition have highlighted the exposure of local resource management systems to external interventions and events (Cox et al. 2010) and the need to expand theory to understand how those systems cope with such events (Armitage 2005). Resilience scholars have theorized about the importance of slow vs fast moving changes (Janssen et al. 2007) and other disturbance features (Schoon 2008). Scholars have also identified different types of adaptations based on the observation of local experiences (Agrawal 2010, Smit and Skinner 2002). The classifications resulting from this study make a step further in integrating the study of disturbances and responses under a common theoretical framework that is also relevant empirically.

Second, the analysis of coordination responses reveals insights about the division of labor between governance levels in adaptation processes. Most of the coordination responses developed by WUAs consisted on the delegation on or bargaining with external entities. The contribution of multi-level management to adaptive capacity is well understood among scholars and practitioners (Olsson et al. 2004). Less is known about how labor should be divided between governance levels (Frey et al. 2016). The subsidiarity principle in the context of environmental governance states that management decisions should occur at the lowest level at which they can be performed competently (Marshall 2008). Resilience scholars have used this principle to argue for a fit between the scale at which disturbances occur and the governance level at which they should be addressed (Levin et al. 1998). In this study, WUAs tended to recur to external entities in the advent of external disturbances; delegation responses tended to address frequent disturbances, while bargaining responses followed infrequent ones. All this supports the fit hypothesis and encourages looking at both the origin and frequency of disturbances when studying the division of labor between governance levels. Finally, the reliance of WUAs on external entities did not preclude that WUAs develop their own responses, which brings the question of the appropriate degree of complementarity and redundancy across governance levels (Low et al. 2003). This study was not designed to address that question; however, the assessment of disturbances and responses in terms of risk of opportunism and collective action costs, respectively, shall be useful for that purpose.

Another insight is related to the only relative importance of new rule development (i.e., as opposed to the adaptation of existing rules and non-institutional responses) to address disturbances. Institutional design, i.e., the implementation of new policies, is one of the 
cornerstones climate change adaptation (see Roggero et al., in this issue for an overview of the climate adaptation literature). In this study, however, new rule development occurred in only $24 \%$ of the occasions. Also, the "ad hoc use of preexisting institution" occurred in $16 \%$ of the cases, which illustrates that given institutions can be reinterpreted to uncover situations for which those institutions had not been originally designed. This type of institutional change, which has been coined by path dependency scholars in different ways (Streeck and Thelen 2005) has barely been explored by adaptation scholars. As framed in this study, the "ad hoc use of preexisting institution" is a relatively low cost adaptation strategy; however, its association mostly to the occurrence of internal and progressive threats suggests that such strategy may not be suitable in all occasions.

Last but not least, the QCA results illustrate opportunities and limits of using transaction costs economics to understand adaptation. According to the analysis, disturbances that are asset specific, intense but frequent, and exogenous (e.g., droughts in this study) are sufficient to trigger cooperative responses. This supports expectations based on transaction costs theory. According to Williamson (Williamson 1985), cooperative governance arrangements are more likely to emerge given asset specific and uncertain transactions, or given asset specific and frequent transactions. In the first case, the high costs and high probability of contract failure would make risk sufficiently high to make cooperation worth it, even if cooperation costs are high. In the second case, frequency would reduce the costs of cooperation, which would pave the way for cooperation, given high costs of contract failure (and regardless of the probability of such failure). According to the QCA findings, both uncertainty (i.e., created by intense disturbances) as well as the profitability of economies of scale (i.e., stemming from frequent disturbances) would be sufficient to trigger cooperation, given that asset specific assets are at risk. Additionally, the findings point to an alternative path, which is the occurrence of progressive and internal disturbances, regardless of their asset specificity (i.e., crop intensification, lack of labor factor, debtors). This path is rather congruent with relational theory, which aims to explain cooperation by looking at the formation of trust relationships rather than the minimization of opportunistic behavior (Lui et al. 2009). In contrast to transaction costs theory, relational theory builds on the assumption that economic agents are willing to commit to long term cooperative relationships with each other if necessary (Joshi and Stump 1999). Behavior in trust-based relationships is controlled not through incentives but through internalization. Thus, time and the credibility of partners are essential. According to this, disturbances that unfold progressively would allow for sufficient time to develop cooperative solutions incrementally if necessary, and provide a long enough time horizon that make those solutions cost-appealing in the short term. Additionally, if the disturbances originate within a community, members could more easily build on their physical proximity, internal norms and trust relationships than if the disturbances are originated by outsiders. Given these conditions, even a minimum of asset specificity would make cooperation worth it.

\section{Conclusions}

Other than the specific findings reported and discussed in the previous sections, this study triggers some final reflections. First, it is still unclear in the adaptation scholarship whether climate change adaptation challenges are fundamentally different from other types

of events that hit our societies at different scales. This study has illustrated that societies 
(e.g., natural resource management communities and associations) opt for different collective adaptation responses depending on the risks of opportunism and collective action costs involved, and regardless of whether the disturbances are climate-related or not.

Second, an important step to compare adaptation to different disturbances and develop solid adaptation theory is the use of meaningful classifications of events and responses. Previous studies have pointed to different ways to characterize disturbances (Salafsky et al. 2008, Schoon and Cox 2011), but there is no theory about how these disturbance features combine in real scenarios and align with responses. As illustrated in this study, the CoaseOstrom-Williamson (COW) framework reveal as powerful means to construct such classifications.

Third, transaction costs theory is relevant but should not be used as the only theoretical pillar to understand disturbances and adaptation responses. Relational theory, which looks at social capital dynamics, can be also useful. Although transaction costs and relational theory can be interpreted as antagonistic, scholars have proposed models that integrate both (Joshi and Stump 1999). Adaptation studies shall benefit from those efforts. As illustrated in this study, the observation of disturbance characteristics can help to understand when one theory is more applicable than the other.

As a final reflection, this study illustrates the capacity of local organizations to respond to a variety of disturbances, including climate-related ones as well as many others. Irrigation associations and other local natural resource management organizations in many countries are depositaries of extensive adaptation experience and knowledge, which stems from their long exposure to a variety of threats to their organizational performance and sustainability over time. Being able to capitalize on that knowledge is a priority for the policy community (UN/ISDR 2004).

\section{References}

Agrawal, A. (2010), 'Local institutions and adaptation to climate change' in Mearns, R. and Norton, A., eds., Social Dimensions of Climate Change, Washington D.C: The Word Bank, pp. 173199.

Anderies, J. M., P. Ryan and B. H. Walker (2006), 'Loss of Resilience, Crisis, and Institutional Change: Lessons from an Intensive Agricultural System in Southeastern Australia', Ecosystems, 9(6): 865-878.

Araral, E. (2013a), 'Does geography matter to institutional choice? A comparative study of ancient commons', Geoforum, 44: 224-231.

Araral, E. (2013b), 'A transaction cost approach to climate adaptation: Insights from Coase, Ostrom and Williamson and evidence from the 400-year old zangjeras', Environmental Science \& Policy, 25: 147-156.

Araral, E. (2013c), 'What makes socio-ecological systems robust? An institutional analysis of the 2,000 year-old Ifugao society', Human Ecology, 41(6): 859-870.

Armitage, D. (2005), 'Adaptive capacity and community-based natural resource management', Environmental management, 35(6): 703-715.

Berkes, F., J. Colding and C. Folke, eds. (2003), Navigating Social-Ecological Systems: Building Resilience for Complexity and Change, New York, NY: Cambridge University Press.

Boken, V. K., A. P. Cracknell and R. L. Heathcote (2005), Monitoring and Predicting Agricultural Drought, New York: Oxford University Press.

Bowles, S. (2009), Microeconomics: behavior, institutions, and evolution, Princeton University Press. 
CESA (2012), Informe socioeconómico de la década 2001-2010 en Aragón, Zaragoza: Consejo Económico y Social de Aragón.

Coleman, E. A. and B. C. Steed (2009), 'Monitoring and sanctioning in the commons: An application to forestry', Ecological Economics, 68(7): 2106-2113.

Cox, M. (2014), 'Modern disturbances to a long-lasting community-based resource management system: The Taos Valley acequias', Global Environmental Change, 24(0): 213-222.

Cox, M., G. Arnold and S. Villamayor Tomás (2010), 'A review of design principles for community-based natural resource management', Ecology and Society, 15(4): 38.

Fehr, E. (2004), 'Human behaviour: don't lose your reputation', Nature, 432(7016): 449-450.

Fleischman, F., K. Boenning, G. A. Garcia-Lopez, S. Mincey, M. Schmitt-Harsh, K. Daedlow, M. C. Lopez, X. Basurto, B. Fischer and E. Ostrom (2010), 'Disturbance, response, and persistence in self-organized forested communities: analysis of robustness and resilience in five communities in southern Indiana', Ecology and Society, 15(4): 9.

Fowler, J. H. (2005), 'Human cooperation: second-order free-riding problem solved?', Nature, 437(7058): E8-E8.

Frey, U. J., S. Villamayor-Tomas and I. Theesfeld (2016), 'A continuum of governance regimes: A new perspective on co-management in irrigation systems', Environmental Science \& Policy, 66: 73-81.

Hagedorn, K. (2008), 'Particular requirements for institutional analysis in nature-related sectors', European Review of Agricultural Economics, 35(3): 357-384.

Janssen, M. A., J. M. Anderies and E. Ostrom (2007), 'Robustness of Social-Ecological Systems to Spatial and Temporal Variability', Society \& Natural Resources: An International Journal, 20(4): 307 - 322.

Joshi, A. W. and R. L. Stump (1999), 'Determinants of commitment and opportunism: Integrating and extending insights from transaction cost analysis and relational exchange theory', Canadian Journal of Administrative Sciences/Revue Canadienne des Sciences de l'Administration, 16(4): 334-352.

Lam, W. and E. Ostrom (2010), 'Analyzing the dynamic complexity of development interventions: lessons from an irrigation experiment in Nepal', Policy Sciences, 43(1): 1-25.

Lam, W. F. (2006), 'Foundations of a robust social-ecological system: irrigation institutions in Taiwan', Journal of Institutional Economics, 2(02): 203-226.

Levin, S., S. Barrett, S. Aniyar, W. Baumol, C. Bliss, B. Bolin, P. Dasgupta, P. Ehrlich, C. Folke, M. Grenning, C. S. Holling, A. Jansson, B.-O. Jansson, K. Ler, D. Martin, C. Perrings and E. Sheshinski (1998), 'Resilience in natural and socioeconomic systems', Environment and Development Economics, 3(02): 221-262.

Lopez Galvez, J. and J. M. Naredo, eds. (1997), La Gestion del Agua de Riego, Madrid: Fundacion Argentaria.

Low, B., E. Ostrom, C. Simon and J. Wilson (2003), 'Redundancy and Diversity: do they influence optimal management?' in Berkes, F., Colding, J. and Folke, C., eds., Navigating SocialEcological Systems, 83-105.

Lui, S. S., Y.-y. Wong and W. Liu (2009), 'Asset specificity roles in interfirm cooperation: Reducing opportunistic behavior or increasing cooperative behavior?', Journal of Business Research, 62(11): 1214-1219.

Marshall, G. (2008), 'Nesting, subsidiarity, and community-based environmental governance beyond the local scale', International Journal of the Commons, 2(1): 75-97.

Menard, C. (2007), 'Cooperatives: hierarchies or hybrids?' in Vertical markets and cooperative hierarchies, Springer, pp. 1-18.

Olsson, P., C. Folke and F. Berkes (2004), 'Adaptive Comanagement for Building Resilience in Social-Ecological Systems', Environmental Management, 34(1): 75-90. 
Osés-Eraso, N., F. Udina and M. Viladrich-Grau (2008), 'Environmental versus Human-Induced Scarcity in the Commons: Do They Trigger the Same Response?', Environmental and Resource Economics, 40(4): 529-550.

Ostrom, E. (1990), Governing The Commons, New York: Cambridge University Press.

Ostrom, E., R. Gardner and J. Walker (1994), Rules, Games and Common Pool Resources, Michigan: Michigan University Press.

Panchanathan, K. and R. Boyd (2004), 'Indirect reciprocity can stabilize cooperation without the second-order free rider problem', Nature, 432(7016): 499-502.

Pinilla Navarro, V. and L. A. Saez Perez (2009), Tendencias recientes en la evolucion de las comarcas aragonesas, Zaragoza: Publicaciones de Rolde de Estudios Aragoneses.

Ragin, C. (2000), Fuzzy-Set Social Science, Chigaco: The University of Chicago Press.

Ragin, C., C. and J. Sonnett (2004), 'Between Complexity and Parsimony: Limited Diversity, Counterfactual Cases, and Comparative Analysis' in kropp, S. and Minkenberg, M., eds., Vergleichen in Der Politikwissenschaft, Wiesbaden: VS Verlag für Sozialwissenschaften, pp.

Salafsky, N., D. Salzer, A. J. Stattersfield, C. Hilton-Taylor, R. Neugarten, S. H. M. Butchart, B. Collen, N. Cox, L. L. Master, S. O'Connor and D. Wilkie (2008), 'A Standard Lexicon for Biodiversity Conservation: Unified Classifications of Threats and Actions', Conservation Biology, 22(4): 897-911.

Santoro, M. D. and J. P. McGill (2005), 'The effect of uncertainty and asset co-specialization on governance in biotechnology alliances', Strategic Management Journal, 26(13): 1261-1269.

Schneider, C. Q. and C. Wagemann (2010), 'Standards of Good Practice in Qualitative Comparative Analysis (QCA) and Fuzzy-Sets', Comparative Sociology, 9(3): 397-418.

Schoon, M. (2008) Building robustness to disturbance: Governance in southern African peace parks, unpublished thesis Indiana University.

Schoon, M. L. and M. E. Cox (2011), 'Understanding Disturbances and Responses in SocialEcological Systems', Society \& Natural Resources, 25(2): 141-155.

Smit, B. and M. Skinner (2002), 'Adaptation options in agriculture to climate change: a typology', Mitigation and Adaptation Strategies for Global Change, 7(1): 85-114.

Streeck, W. and K. Thelen (2005), 'Introduction: Institutional Change in Advanced Political Economies' in Streeck, W. and Thelen, K., eds., Beyond Continuity: Institutional Change in Advanced Political Economies, New York: Oxford University Press, pp. 3-39.

Tang, S. Y. (1992), Institutions and Collective Action: Self-Governance in Irrigation California: Institution for Contemporary Studies.

Thiel, A., C. Schleyer, J. Hinkel, M. Schlüter, K. Hagedorn, S. Bisaro, I. Bobojonov and A. Hamidov (2016), 'Transferring Williamson's discriminating alignment to the analysis of environmental governance of social-ecological interdependence', Ecological Economics, 128: $159-168$.

UN/ISDR (2004), Living with Risk: A Global Review of the International Strategy for Disaster Reduction, Geneva, Switzerland: United Nations Office for Disaster Risk Reduction (UNISDR).

Varela-Ortega, C., I. Blanco-Gutiérrez, P. Esteve, S. Bharwani, S. Fronzek and T. E. Downing (2016), 'How can irrigated agriculture adapt to climate change? Insights from the Guadiana Basin in Spain', Regional Environmental Change, 16(1): 59-70.

Villamayor-Tomas, S. (2014), 'Cooperation in common property regimes under extreme drought conditions: Empirical evidence from the use of pooled transferable quotas in Spanish irrigation systems', Ecological Economics, 107(0): 482-493.

Williamson, O. (1985), The Economic Institutions of Capitalism, New York: Free Press.

Williamson, O. E. (1991), 'Comparative economic organization: The analysis of discrete structural alternatives', Administrative science quarterly: 269-296. 


\section{Appendix}

\section{Illustration of variable measurement and coded case}

The case response cases were created based on three sources of data: meeting minutes from the executive committee and general assemblies (1970-2010); a focus group interview with members of the executive committee of each irrigation association; and individual interviews with members of the executive committee and farmers. Focus groups and group interviews in general are recommendable when the topic of interest is habit or not thought in detail by participants; however, individual interviews may still be necessary for triangulation purposes (Morgan 1997). Scanning the meeting minutes was not allowed so relevant pieces of text were recorded and then transcribed. Individual interviewees were selected according following a snowball procedure. All the group and individual interviews were recorded. The recordings were used to enhance the notes taken during the interviews. The formal characterization of cases was carried by person. The use of multiple coders adds reliability to measurement, which is appropriate if data is collected only from one source and there are potential issues of interpretation. In this study, all facts from the minutes were checked via the focus groups. Remaining gaps were filled through the individual interviews.

\section{Case 42 (Internal progressive cooperation threat \& Use of existing rule response)} Summary:

- Disturbance: In old irrigation systems like the FVT, there are many small, secondary and tertiary ditches that bring water to the plots or collect drained water. Over time, compliance with the maintenance duties of these ditches has decreased. This is an labor-intense work that can be done with machines only to some extent. Agriculture is not a full time for an increasing number of farmers and there is less labor available to carry the maintenance duties. If the ditches are not cleaned water does not flow properly and this generates water allocation problems.

- $\quad$ Response 1: When a farmer does not comply with his maintenance duties and this is detected by the guard, the association has the authority to carry the duties and then charge the farmer accordingly. As the problem of lack of compliance scaled up, the association started acting only if any farmers complained.

Disturbance characteristics

\begin{tabular}{|l|c|}
\hline Water use specific & + \\
\hline Water use specific & \\
\hline Infrastructure specific & + \\
\hline Intensity & \\
\hline Exogeneity & \\
\hline Frequency & \\
\hline
\end{tabular}

Meeting minutes:

"Given the continuous complains related to the bad conditions of the drainage ditches of this association, it has been agreed by unanimity to find a solution..." (September 1973)

"...it is debated the continuous increase of living costs and the need to update the payments to the labor that is hired to assist the cleaning of the infrastructure...” (September 1976)

"The President expresses his concern about the continuous maintenance issues associated to the increasing difficulties for farmers to carry their duties manually...” (April 1989)

"Sr. F.P. complains about the maintenance issues in the Masarrabal ditch. There is a section of that ditch were farmers do not carry their maintenance duties and this causes continuous water spills with important damages to the neighbors..." (July 1997)

Executive committee focus group:

"drainage ditches are shared in common by groups of farmers...farmers were more and more disinterested in cleaning them... they would not do it themselves and would not hire labor to do it..."

“...if the drainage ditches are not clean, water does not flow and it floods the fields..."

“...it was all part of a social change... before, a plot was managed by a family but now farmers need to cultivate more land and there is not enough labor...cleaning is not a nice work... before there were many people who would do it for money, but this has changed...the issue has also to do with 
the migration of people from the village to Barcelona; the land is abandoned and the maintenance duties too” (2011-12-23_FVT_JRC)

Interviews:

“...before everyone would carry the maintenance duties; it was a matter of reputation and respect. Now that is not anymore the case. Fewer people work full time in this system... now people use machines but machines cannot reach every corner of the system” (2011-12-05_FVT_JN) “...the problem emerged progressively since the 1970s...currently, given how spread out the problem is, the executive committee only acts if a farmer files a complain” (2011-12-05_FVT_O)

Response characteristics

\begin{tabular}{|l|c|}
\hline Communication & + \\
\hline Collective choice & + \\
\hline Rule enforcement & \\
\hline Contribution enforcement & \\
\hline
\end{tabular}

\section{Meeting minutes:}

“... the association lawyer is consulted about the issue of water filtrations and springs that are emerging all around the system due to the problem of lack of maintenance of drainage systems... after a long debate about it Sr. S. informs that he will study how to proceed" (June 1986)

"Given the bad conditions of the ditch between Calle Alabon and Cami Petit... attendants to the meeting agree to formally request the cleaning of the ditch to the responsible farmers warning them that in 30 days the association will carry the cleaning if they do not do it, and then will charge the farmers accordingly" (January 1996)

"Given the complaint against Dr. C.P... attendants agree by unanimity to formally request Dr. C.P. to carry the maintenance duties in the next 15 days, or else the association will do it and pass the costs plus an extra charge to the farmer" (September 1995)

\section{Executive committee focus group:}

“...initially, the neighbors would clean the ditches of the absent neighbors and then charged the neighbors accordingly but as the problem scaled up that solution proved ineffective... at some point, the association started doing the job if any farmer would complain and would charge the neighbor afterwards...the association had a squad of laborers already

(2011-12-23_FVT_JRC)

\section{Interviews:}

“...before the maintenance was carried by the farmers. The guard would monitor it and would carry the cleaning if farmers had not done it... bit a bit people stopped doing it and the problem scaled up...currently the executive committee only acts if someone complains" (2011-12-

05_FVT_AG)

“...more and more farmers started piping their sections of the ditches...so the executive committee decided to set some standards. Farmers would need to notify the executive committee, the guard would pay a visit to the site and then the committee would give technical advice and make a resolution of approving or not the works” (2011-11-05_FVT_O) 
Table 1: Database of Disturbance-response cases

\begin{tabular}{|c|c|c|c|c|c|c|c|c|c|c|c|c|}
\hline ID & WUA & Disturbance & Response Type & Outcome & $\begin{array}{l}\text { Asset } \\
\text { Specif. }\end{array}$ & Intens. & Frequ. & Exogen. & Comm. & $\begin{array}{l}\text { Coll. } \\
\text { choice }\end{array}$ & $\begin{array}{l}\text { Rule } \\
\text { enforc. }\end{array}$ & $\begin{array}{l}\text { Contrib. } \\
\text { Enforc. }\end{array}$ \\
\hline 1 & SXI & Drought & Investment \& rule & 1 & 1 & 1 & 1 & 1 & 1 & 1 & 1 & 1 \\
\hline 2 & SXI & Drought & Rule development & 1 & 1 & 1 & 1 & 1 & 1 & 1 & 1 & 0 \\
\hline 3 & SXI & Crop intensification & Investment \& rule & 1 & 1 & 0 & 0 & 0 & 1 & 1 & 1 & 1 \\
\hline 4 & SXI & Crop intensification & Investment \& rule & 1 & 1 & 0 & 0 & 0 & 1 & 1 & 1 & 1 \\
\hline 5 & SXI & Crop intensification & Delegation on external entity & 0 & 1 & 0 & 0 & 0 & 1 & 1 & 0 & 0 \\
\hline 6 & SXI & Crop intensification & Delegation on external entity & 0 & 1 & 0 & 0 & 0 & 1 & 1 & 0 & 0 \\
\hline 7 & SXI & Lack of labor factor & Investment \& rule & 1 & 1 & 0 & 0 & 0 & 1 & 1 & 1 & 1 \\
\hline 8 & SXI & Energy price crisis & Rule development & 1 & 0 & 1 & 0 & 1 & 1 & 1 & 1 & 0 \\
\hline 9 & SXI & Energy price crisis & Bargaining with external entities & 0 & 0 & 1 & 0 & 1 & 1 & 1 & 0 & 0 \\
\hline 10 & SXI & Debtors & Use of existing rule & 1 & 0 & 0 & 0 & 0 & 1 & 0 & 1 & 0 \\
\hline 11 & SXI & Debtors & Use of existing rule & 1 & 0 & 0 & 0 & 0 & 1 & 0 & 1 & 0 \\
\hline 12 & JC & Drought & Rule development & 1 & 1 & 1 & 1 & 1 & 1 & 1 & 1 & 0 \\
\hline 13 & $\mathrm{JC}$ & Crop intensification & Rule development & 1 & 1 & 0 & 0 & 0 & 1 & 1 & 1 & 0 \\
\hline 14 & $J C$ & Crop intensification & Delegation on external entity & 0 & 1 & 0 & 0 & 0 & 1 & 1 & 0 & 0 \\
\hline 15 & $\mathrm{JC}$ & Crop intensification & Investment \& rule & 1 & 1 & 0 & 0 & 0 & 1 & 1 & 1 & 1 \\
\hline 16 & $\mathrm{JC}$ & Highway/railway isues & Bargaining with external entities & 0 & 0 & 1 & 0 & 1 & 1 & 1 & 0 & 0 \\
\hline 17 & JC & New water users & Bargaining with external entities & 0 & 0 & 1 & 1 & 1 & 1 & 1 & 0 & 0 \\
\hline 18 & JC & New water users & Rule development & 1 & 0 & 1 & 1 & 1 & 1 & 1 & 1 & 0 \\
\hline 19 & JC & Lack of labor factor & Use of existing rule & 1 & 1 & 0 & 0 & 0 & 1 & 0 & 1 & 0 \\
\hline 20 & JC & Canal breakages & Delegation on external entity & 0 & 0 & 1 & 1 & 1 & 1 & 1 & 0 & 0 \\
\hline 21 & $\mathrm{JC}$ & Canal breakages & Delegation on external entity & 0 & 0 & 1 & 1 & 1 & 1 & 1 & 0 & 0 \\
\hline 22 & $\mathrm{CV}$ & Drought & Rule development & 1 & 1 & 1 & 1 & 1 & 1 & 1 & 1 & 0 \\
\hline 23 & $\mathrm{CV}$ & Lack of labor factor & Use of existing rule & 1 & 1 & 0 & 0 & 0 & 1 & 0 & 1 & 0 \\
\hline 24 & $\mathrm{CV}$ & Lack of labor factor & Investment & 1 & 1 & 0 & 0 & 0 & 1 & 1 & 0 & 1 \\
\hline
\end{tabular}




\begin{tabular}{|c|c|c|c|c|c|c|c|c|c|c|c|c|}
\hline 25 & $\mathrm{CV}$ & Highway/railway issues & Bargaining with external entities & 0 & 0 & 1 & 0 & 1 & 1 & 1 & 0 & 0 \\
\hline 26 & $\mathrm{CV}$ & Urbanization events & Bargaining with external entities & 0 & 0 & 1 & 0 & 1 & 1 & 1 & 0 & 0 \\
\hline 27 & $\mathrm{CV}$ & Urbanization events & Use of existing rule & 1 & 0 & 1 & 0 & 1 & 1 & 0 & 1 & 0 \\
\hline 28 & $\mathrm{CV}$ & Landslides & Ad-hoc mitigation & 0 & 0 & 1 & 1 & 1 & 1 & 1 & 0 & 0 \\
\hline 29 & $\mathrm{CV}$ & Landslides & Delegation on external entity & 0 & 0 & 1 & 1 & 1 & 1 & 1 & 0 & 0 \\
\hline 30 & $\mathrm{CV}$ & Bad drainage-storm & Delegation on external entity & 0 & 1 & 0 & 0 & 1 & 1 & 1 & 0 & 0 \\
\hline 31 & $\mathrm{CV}$ & River flood & Investment & 1 & 0 & 1 & 1 & 1 & 1 & 1 & 0 & 1 \\
\hline 32 & $\mathrm{CV}$ & Highway/railway issues & Delegation on external entity & 0 & 1 & 1 & 0 & 1 & 1 & 1 & 0 & 0 \\
\hline 33 & SA & Drought & Delegation on external entity & 0 & 1 & 1 & 1 & 1 & 1 & 1 & 0 & 0 \\
\hline 34 & SA & Lack of labor factor & Ad-hoc mitigation & 0 & 1 & 0 & 0 & 0 & 1 & 1 & 0 & 0 \\
\hline 35 & SA & Lack of labor factor & Use of existing rule & 1 & 1 & 0 & 0 & 0 & 1 & 0 & 1 & 0 \\
\hline 36 & SA & Urban pollution & Delegation on external entity & 0 & 0 & 0 & 0 & 1 & 1 & 1 & 0 & 0 \\
\hline 37 & SA & Urban pollution & Delegation on external entity & 0 & 0 & 0 & 0 & 1 & 1 & 1 & 0 & 0 \\
\hline 38 & SA & Lake flood & Bargaining with external entities & 0 & 0 & 0 & 0 & 1 & 1 & 1 & 0 & 0 \\
\hline 39 & SA & Lake flood & Investment & 1 & 0 & 0 & 0 & 1 & 1 & 1 & 0 & 1 \\
\hline 40 & SA & Landslides & Ad-hoc mitigation & 0 & 0 & 1 & 1 & 1 & 1 & 1 & 0 & 0 \\
\hline 41 & SA & Landslides & Delegation on external entity & 0 & 0 & 1 & 1 & 1 & 1 & 1 & 0 & 0 \\
\hline 42 & FVT & Lack of labor factor & Ad-hoc mitigation & 0 & 1 & 0 & 0 & 0 & 1 & 1 & 0 & 0 \\
\hline 43 & FVT & Lack of labor factor & Use of existing rule & 1 & 1 & 0 & 0 & 0 & 1 & 0 & 1 & 0 \\
\hline 44 & FVT & Lack of labor factor & Investment \& rule & 1 & 1 & 0 & 0 & 0 & 1 & 1 & 1 & 1 \\
\hline 45 & FVT & Leadership crisis & Delegation on external entity & 0 & 1 & 1 & 0 & 0 & 1 & 1 & 0 & 0 \\
\hline 46 & FVT & Leadership crisis & Use of existing rule & 1 & 1 & 1 & 0 & 0 & 1 & 0 & 1 & 0 \\
\hline 47 & FVT & River flood & Ad-hoc mitigation & 0 & 0 & 1 & 1 & 1 & 1 & 1 & 0 & 0 \\
\hline 48 & FVT & River flood & Delegation on external entity & 0 & 0 & 1 & 1 & 1 & 1 & 1 & 0 & 0 \\
\hline 49 & FVT & Algae & Ad-hoc mitigation & 0 & 0 & 1 & 1 & 0 & 1 & 1 & 0 & 0 \\
\hline 50 & FVT & Highway/railway issues & Bargaining with external entities & 0 & 0 & 1 & 0 & 1 & 1 & 1 & 0 & 0 \\
\hline
\end{tabular}


Table 2: Truth table for full dataset

\begin{tabular}{l|ccc|cc}
$\begin{array}{l}\text { Configuration } \\
\#\end{array}$ & $\begin{array}{c}\text { Asset } \\
\text { specificity }\end{array}$ & Intensity & Exogeneity & $\mathrm{n}_{\mathrm{drc}}$ & $\begin{array}{c}\text { Configuration } \\
\text { consistency }\end{array}$ \\
\hline 1 & 0 & 0 & 0 & 2 & 1 \\
2 & 1 & 1 & 1 & 6 & 0.833 \\
3 & 1 & 0 & 0 & 16 & 0.688 \\
4 & 1 & 1 & 0 & 2 & 0.5 \\
5 & 0 & 0 & 1 & 4 & 0.250 \\
6 & 0 & 1 & 1 & 18 & 0.222 \\
7 & 0 & 1 & 0 & 1 & 0 \\
8 & 1 & 0 & 1 & 1 & 0 \\
\hline
\end{tabular}

Table 3: Truth table for intense disturbances dataset

\begin{tabular}{l|ccc|cc}
$\begin{array}{l}\text { Configuration } \\
\#\end{array}$ & $\begin{array}{c}\text { Asset } \\
\text { specificity }\end{array}$ & Frequency & Exogeneity & $\mathrm{n}_{\mathrm{drc}}$ & $\begin{array}{c}\text { Configuration } \\
\text { consistency }\end{array}$ \\
\hline 1 & 1 & 1 & 1 & 5 & 1 \\
2 & 1 & 0 & 0 & 2 & 0.5 \\
3 & 0 & 0 & 1 & 7 & 0.286 \\
4 & 0 & 1 & 1 & 11 & 0.182 \\
5 & 0 & 1 & 0 & 1 & 0 \\
6 & 1 & 0 & 1 & 1 & 0 \\
\hline
\end{tabular}

Table 4: Configurations of disturbance characteristic that are sufficient for cooperation (parsimonious solution)

Full sample

\begin{tabular}{ll}
\hline Presence of cooperation & Absence of cooperation \\
\hline $\begin{array}{l}\text { ASSET SPECIFIC*FREQUENT*EXOGENOUS } \\
\text { Consistency: 0.883; Coverage: } 0.208\end{array}$ & $\begin{array}{l}\text { asset specific*INTENSE } \\
\text { Consistency: 0.789; Coverage: } 0.577\end{array}$ \\
$\begin{array}{l}\text { Asset specific*intense*exogenous } \\
\text { Consistency: } 1.0 . ; \text { Coverage: } 0.083\end{array}$ & $\begin{array}{l}\text { intense*EXOGENOUS } \\
\text { Consistency: } 0.8 ; \text { Coverage: } 0.154\end{array}$ \\
Intense disturbances sample & \\
\hline Presence of cooperation & Absence of cooperation \\
\hline $\begin{array}{l}\text { ASSET SPECIFIC*FREQUENT } \\
\text { Consistency: 1.0; Coverage: } 0.5\end{array}$ & $\begin{array}{l}\text { asset specific } \\
\text { Consistency: } 0.789 ; \text { Coverage: } 0.882\end{array}$ \\
& frequent*EXOGENOUS \\
& Consistency: $0.75 ;$ Coverage: 0.353 \\
\hline
\end{tabular}

Note: Upper case letters=presence of condition; Lower case letter=absence of condition

Table 5. Configurations of disturbance characteristics that are sufficient for the absence of cooperation, in addition to any configuration of not asset specific disturbances

$\mathrm{n}_{\mathrm{drc}} \quad$ Disturbances 


\begin{tabular}{|c|c|c|}
\hline \multicolumn{3}{|l|}{ Full sample } \\
\hline $\begin{array}{l}\text { 1. intense*EXOGENOUS } \\
\text { Consistency: } 0.8 \\
\text { Coverage: } 0.154\end{array}$ & 5 & Bad road maintenance, urban pollution, lake flood \\
\hline \multicolumn{3}{|l|}{ Intense disturbances sample } \\
\hline $\begin{array}{l}\text { 2. frequent* EXOGENOUS } \\
\text { Consistency: } 0.75 \\
\text { Coverage: } 0.353\end{array}$ & 8 & $\begin{array}{l}\text { Urbanization issues, highway/railway development, } \\
\text { energy crisis, bad road maintenance }\end{array}$ \\
\hline
\end{tabular}

Note: Upper case letters=presence of condition; Lower case letter=absence of condition.

The analysis of sufficiency yielded two other solutions (one per sample), that observed the absence of asset specificity. These solutions are not shown in the table for clarity purposes, given the findings from the necessity analysis.

Table 6: Configurations of disturbance features that are sufficient for cooperation (aggregated data; complex solution)

\section{Full sample}

\begin{tabular}{ll}
\hline Presence of cooperation & Absence of cooperation \\
\hline $\begin{array}{l}\text { ASSET SPECIFIC*INTENSE*EXOGENOUS } \\
\text { Consistency: 0.8; Coverage: } 0.289\end{array}$ & $\begin{array}{l}\text { asset specific*INTENSE } \\
\text { Consistency: 0.792 ; Coverage: } 0.626\end{array}$ \\
$\begin{array}{ll}\text { Intense*exogenous } \\
\text { Consistency: 0.792; Coverage: } 0.458\end{array}$ & $\begin{array}{l}\text { intense*EXOGENOUS } \\
\text { Consistency: 0.833; Coverage: } 0.156\end{array}$ \\
Intense disturbances sample & \\
\hline Presence of cooperation & Absence of cooperation \\
\hline $\begin{array}{l}\text { ASSET SPECIFIC*FREQUENT*EXOGENOUS } \\
\text { Consistency: 1.0; Coverage: } 0.533\end{array}$ & $\begin{array}{l}\text { asset specific*FREQUENT } \\
\text { Consistency: 0.786 ; Coverage: } 0.478\end{array}$ \\
& $\begin{array}{l}\text { frequent*EXOGENOUS } \\
\text { Consistency: } 0.786 \text {; Coverage: } 0.478\end{array}$ \\
\hline
\end{tabular}

Note: Data was aggregated by the mean to better capture potential interactions between responses of one association to the same disturbance. Data was also aggregated according to a maximum rule (a 1 was assigned if at least one cooperation response was present). The results were very similar (available upon request); Upper case letters=presence of condition; Lower case letter=absence of condition 